\title{
DITOPHAL* IN THE TREATMENT OF LEPROSY
}

\author{
By K. F. Schaller, \\ Director of Princess Zenehe Work Hospital, Addis Ahaha \\ and \\ C. SERIÉ, \\ Director of Institut Pasteur of Ethiopia
}

\section{History}

DAviES and Driver (1956) investigated a claim that a mixture of certain thiol compounds prevented the development of tuberculosis in guinea-pigs (DEL Pianto, 1950) and they discovered that the active principle involved was ethyl mercaptan. This property was possessed only by the ethyl homologue. They concluded that a derivative of ethyl mercaptan which was acceptable clinically and pharmaceutically and which liberated ethyl mercaptan in the body at the optimum rate should be effective against the mycobacterial diseases such as lupus, tuberculosis and leprosy. Ditophal was eventually chosen from about 400 ethyl mercaptan derivatives (DAviEs and Driver 1957).

The antituberculosis action of Ditophal is due to the release of ethyl mercaptan in the body, but neither compound shows any antituberculosis activity in vitro. Both are, however, very effective against intracellular bacteria, ethyl mercaptan inhibiting the growth of $M$. tuberculosis in an infected monocyte culture at $10 \gamma / \mathrm{ml}$. The action of the ethyl mercaptan derivatives is antagonised by the methyl analogues and it is thought that ethyl mercaptan acts by interfering with a metabolic pathway which involves methyl or methylthio groups and whic'h is present either in the monocyte or is part of the specific metabolism of the bacillus in the monocyte. The metabolism of Ditophal and of ethyl mercaptan has been studied in laboratory animals using $\mathrm{C}^{\mathbf{1 4}}$ and $\mathrm{S}^{35}$-labelled drug and almost all the administered drug has been accounted for without finding a metabolite with antituberculous activity (Lowe 1960, SNOw 1957).

Ditophal is effective in laboratory animals when administered either parenterally or orally but it is more effective by the former route. Oral dosing gives rise to ethyl mercaptan in the gastrointestinal tract and some of this escapes giving an unpleasant smell. The drug has the unique property of being rapidly absorbed through the skin, thus offering a novel method of parenteral administration in leprosy while avoiding the difficulties associated with injection. This method of administration appeared to be peculiarly suited to the treatment of leprosy and lupus vulgaris and NAGUIB and ROBSON

\footnotetext{
* Ditophal ('Etisul' I.C.I.)
} 
(1956) had already shown it to be outstandingly active against intracorneal infections of murine leprosy in the mouse and it was completely non-toxic.

\section{Chemistry}

Chemically Ditophal is diethyl-dithiolisophthalate. It is a bland oily liquid with a garlic-like odour and has the unique property of high systemic activity after percutaneous absorption (following inunction into the skin). For the purpose of inunction Ditophal is presented in either cream or liquid formulation based on an activeagent content of $5 \mathrm{~g}$. per dose and suitably perfumed to mask the intrinsic odour.

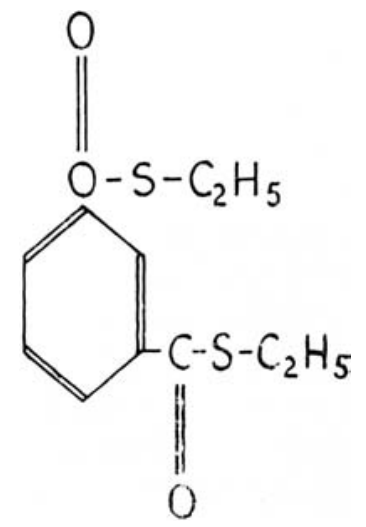

\section{Previous Clinical Work in Leprosy}

Ditophal began to be clinically used in 1957. Davey (1958) first reported his early impressions from Nigeria to the VIlth International Congress of Leprology in Tokyo. Later (DAVEY and Hogerzeil 1959, Davey 1959 \& 1960) he published his experiences in greater detail and at a later stage of development. Ditophal was at first used alone, but later its greatest usefulness was found to lie in combined use with DDS or DPT ( = SU 1906), where it materially reduced the period of time in which bacteriological and clinical improvement is obtained, compared with the length of time taken by these drugs, alone, to produce similar results. From experience, by trial and error, in a total of 133 patients DAVEY suggested that the best time to introduce Ditophal would be at a stage when full DDS maintenance dosage has been reached, and that the two drugs should then be given together for about 3 months.

LECHAT (1959) in the Belgian Congo obtained equally favourable results in 28 lepromatous cases and found the cream readily accepted by all his patients.

Ross (1960) in Northern Nigeria found the bacterial index to 
decline rapidly in 28 lepromatous and borderline cases, treated thrice weekly for 5 months.

Gabriel (1959/60), in 8 patients in Queensland, obtained results which made him regard Ditophal as an extremely useful drug, since its use considerably reduces the time required for clinical improvement to become apparent and for a negative phase of the disease to be reached.

JAMISON and PALMER (1960) in 6 cases in Northern Nigeria, saw the bacilli disappear completely or almost completely, as well as finding marked histological improvement in leprous skin.

MCGREgor (1961) used Ditophal alone for 12 weeks in 29 lepromatous cases in Sarawak (twice-weekly inunctions) and saw clinical and bacteriological improvement well beyond the level experienced with other drugs in that length of time. This rate of improvement persisted after change-over to basic treatment.

ThangaraJ and Thangaraj (1961) obtained excellent results in 6 fresh lepromatous cases at Purulia, India, who received Ditophal together with parenteral sulphone.

All reports to date are unanimous in pointing to the lack of any side effects and signs of toxicity.

\section{Personal Experiences}

A trial of Ditophal in combination with DDS was begun at the Princess Zenebe Work Hospital, Addis Ababa in September 1959. 19 patients were treated, of whom 18 were of the lepromatous type and 1 was tuberculoid. There was only 1 female in the group, this being a case suffering from lepromatous leprosy, aged 40, with a history of one year's illness. The tuberculoid case was a man aged 26 with a history of two year's illness before admittance. The remainder of the patients were all lepromatous cases, age varying from 12-46 years and the duration of the disease from 1-7 years.

Diagnosis was made on clinical, bacteriological, immunological and histo-pathological grounds. None of the patients had received any previous treatment. Laboratory tests (bacteriological smears) and histo-pathology were also carried out in the Pasteur Institute, Addis Ababa. The treatment consisted of DDS which was gradually built up to a maintenance dose of $700 \mathrm{mg}$. per week (100 mg. daily), maintenance dosage being reached at the end of the third month. At this stage the patients started to receive Ditophal ointment by inunction, one tube (containing 5 grammes active agent) thrice weekly at equally spaced intervals. 15 cases were treated for the full period of one year ( 52 weeks), 3 cases were treated for 36 weeks and 1 case for 37 weeks only. The total dosage of DDS for those on one year's treatment amounted to 45 grammes and the total dosage of Ditophal to 156 tubes (780 g.). 


\section{Clinical details of cases}

No. 20100-Male-30 years old.

Type of Disease: Lepromatous leprosy-4 years sick before admittance.

Lepromin: Negative. Tuberculin: Negative.

Weight: Slightly increased.

Hansen bacilli: On October, 1959

$$
\begin{array}{ll}
\text { On October, } 1960 & \text { Skin: } \\
& \text { Nose: Negative } \\
& \text { Skin: }
\end{array}
$$

Sedimentation rate: January, 1960-70/115-October, 1960-30/60.

Decrease of bacilli after 6 months of treatment. Lesions less active

Patient feels better. General conditions improved.

TREATMENT: 52 weeks Total of Ditophal: 156 tubes (780 grammes)

Total of D.D.S.: $\quad 54.6 \mathrm{G}$.

No. 20284-Male-20 years old.

Type of Disease: Lepromatous leprosy -5 years sick before admittance.

Lepromin: Negative. Tuberculin: Negative

Weight: unchanged.

Hansen bacilli: On September, 1959 Nose: ++++

On October, 1960 Nose: Negative

Skin: +

After 6 months considerable decrease of bacilli. Sedimentation rate improved.

Reaction after 3 months most probably due to D.D.S. Lepromatous lesions are flattened and less active. Patient feels better since 3 months trophic ulcer on left foot. Clinically improved

TREATMENT: 52 weeks Total of Ditophal: 156 tubes (780 grammes)

Total of D.D.S.: $\quad 54.5 \mathrm{G}$.

No. 18268-Male-20 years old

Type of Disease: Lepromatous leprosy-4 years sick before admittance.

Lepromin: Negative. Tuberculin: Negative.

Hansen bacilli: On September, 1959 Nose: +

On October, 1960 Nose: Negative

Weight increased by $5 \mathrm{~kg}$.

Skin: Negative

Sedimentation rate: January, 1960-57/100 October, 1960—10/23

After 3 months of treatment patients suffer from leprosy reaction. Lepromatous lesions nearly disappeared. Patient feels bettẹr. General conditions improved.

Treatment: 51 weeks and Total of Ditophal: 153 tubes (765 grammes) 3 days. Total of D.D.S.: $45.1 \mathrm{G}$.

No. 20148-Male-26 years old.

Type of Disease: Tuberculoid leprosy -2 years sick before admittance.

Weight: February, 6019, $63 \mathrm{~kg}$. October, 1960, $65 \mathrm{~kg}$.

Hansen bacilli: On October, 1959 Nose: Negative January, 1960:++

Skin: Negative

On October, 1960 Nose: Negative

Sedimentation rate: January, 1960-10/33

Skin: Negative

Loss of sensibility in the right hand of muscular strength. Rheumatic pains which occurred after 10th month of treatment. Now, conditions improved again. Superficial ulcers on both feet which are under treatment. After 3 months patient showed reactionary phase with bacilli ++ , which was followed by a general improvement.

TREATMENT: 51 weeks Total of Ditophal: 153 tubes (765 grammes) Total of D.D.S.: $\quad 45.4$ G.

No. 20027-Male_-23 years old.

Type of Disease: Lepromatous leprosy-5 years sick before admittance.

Lepromin: Negative. Tuberculin: Negative. 
Hansen bacilli: On September, 1959 Nose: ++++

$$
\begin{array}{ll}
\text { Skin: } & +++ \\
\text { Nose: Negative } & \\
\text { Skin: } & \text { Negative }
\end{array}
$$

After 3 months treatment patient got reaction which is followed by decrease of bacilli. The sedimentation rate improved from $45 / 72$ to $11 / 30$. Patient feels much better but still complains of rheumatic pains on his legs and on his arms. Lepromatous lesions are flattened. Clinically improved.

Treatment: 52 weeks Total of Ditophal: 156 tubes (780 grammes) Total of D.D.S.: $45.6 \mathrm{G}$.

No. 20258-Male-22 years old.

Type of Disease: Lepromatous leprosy -6 years sick before admittance.

Lepromin: Negative. Tuberculin: $13 \mathrm{~mm}$.

Weight : unchanged.

Hansen bacilli: On October, 1959

$$
\text { On October, } 1960 \quad \begin{aligned}
& \text { Nose: Negative } \\
& \text { Skin: Negative }
\end{aligned}
$$

Sedimentation rate increased. Leprosy reaction occurred and was controlled by usual treatment. Lepromatous lesions are less active. Patient clinically improved.

TREATMENT: 52 weeks Total of Ditophal: 156 tubes (780 grammes) Total of D.D.S.: $\quad 45.6 \mathrm{G}$.

No. 19835-Male-15 years old.

Type of Disease: Lepromatous leprosy -6 years sick before admittance.

Lepromin: Negative. Tuberculin: Negative.

Weight: $44 \mathrm{~kg}$. now increased by $6 \mathrm{~kg}$.

Hansen bacilli: On September, 1959 Nose:

$$
\begin{array}{ll} 
& \text { Skin: }++ \\
\text { On October, } 1960 & \text { Nose: Negative } \\
& \text { Skin: Negative }
\end{array}
$$

Lepromatous lesions do not show any more activity. Lepromatas are flattened. Clinically patient appears improved but complains still of burning sensations on both legs. Sedimentation rate: June 1960: 45/82 . October, 1960: 20/45.

Treatment: 52 weeks Total of Ditophal: 156 tubes ( 780 grammes) Total of D.D.S.: $\quad 45.6 \mathrm{G}$.

No. 19973-Male-33 years old.

Type of Disease: Lepromatous leprosy.

Lepromin: Negative. Tuberculin: $5 \mathrm{~mm}$.

Hansen bacilli: On September, 1959 Nose: +++

$$
\begin{array}{ll} 
& \text { Skin: }++++ \\
\text { On October, } 1960 & \text { Nose: Negative } \\
& \text { Skin: Negative }
\end{array}
$$

Sedimentation rate: nor far from normal. Leprosy lesions on nose and skin disappeared; also the macular lesions on his back. Patient complains of disturbances in the sensibility on his left leg external surface. Clinically improved.

TREATMENT: 52 weeks Total of Ditophal: 156 tubes ( 780 grammes) Total of D.D.S.: $\quad 45.8 \mathrm{G}$.

No. 20275-Male-27 years old.

Type of disease: lepromatous leprosy -2 years sick before admittance.

Tuberculine: Negative. Lepromin: Negative.

Hansen bacilli: On October, 1959 Skin:

$$
\begin{array}{ll}
\text { On May, } 1960 & \text { Nose: }++ \\
& \text { Skin: }++ \\
& \text { Nose: }+++
\end{array}
$$

Sedimentation rate: October, 1959 80/102. May, 1960 53/100

After 3 months reaction occurred followed by 2 relapses.

No marked improvement.

Treatment: 36 weeks

Total of Ditophal 102 tubes (510 grammes)

Total of D.D.S. $\quad 32.4$ G. 
No. 20126-Male-28 years old.

Type of disease: lepromatous leprosy-5 years sick before admittance.

Lepromin: Negative. Tuberculin: $15 \mathrm{~mm}$.

Hansen bacilli: On October, 1959 Skin: +++

$$
\begin{aligned}
& \text { On October, } 1960 \text { Skin: Negative } \\
& \text { Nose: Negative }
\end{aligned}
$$

After 3 months reaction most probably due to D.D.S. medication. Case is complicated by lymphogranuloma venereum like lesions. Leprosy clinically improved.

TREATMENT: 52 weeks Total of Ditophal: 156 tubes ( 780 grammes)

$$
\text { Total of D.D.S.: } \quad 45.6 \mathrm{G} \text {. }
$$

No. 20101-Male-28 years old.

Type of disease: lepromatous leprosy-7 years sick before admittance.

Tuberculin: Negative. Lepromin: Negative.

Sedimentation rate: October, 1959 30/55. July 1960 40/78.

Hansen bacilli: On October 1959

$\begin{array}{ll}\text { Nose: } & ++ \\ \text { Skin: } & ++\end{array}$

$\begin{array}{ll} & \text { Skin: }+++ \\ \text { On July } 1960 & \text { Nose: }+ \\ & \text { Skin: }++\end{array}$

After 3 months leprosy reaction, case did not show marked improvement.

Treatment: 36 weeks Total of Ditophal: 108 tubes (540 grammes)

Total of D.D.S.: $\quad 32.4$ G.

No. 20247-Male -45 years of age.

Type of disease: Lepromatous leprosy -2 years sick before admittance.

Lepromin: Negative. Tuberculin: Negative.

Hansen bacilli: On October, 1960

$$
\begin{array}{ll} 
& \text { Nose: }++++ \\
\text { On July, } 1960 & \text { Skin: }++ \\
& \text { Nose: Negative }
\end{array}
$$

Sedimentation rate: October, 1959 80/120. July, 1960 40/68.

Reaction after 3 months treatment-relapsed twice, patient is moderately improved.

Treatment: 36 weeks Total of Ditophal: 120 tubes (600 grammes) Total of D.D.S.: $\quad 32.4 \mathrm{G}$.

No. 19512-Male-54 years old.

Type of disease: Lepromatous lepros $y-6$ years sick before admittance.

Lepromin: Negative. Tuberculin: Negative.

Hansen bacilli: On August, 1959 Skin: ++++

Nose:

On November, 1960 Skin: Negative

Nose: Negative

Sedimentation rate: January, 1960 60/120. August, 1960 53/71

Lepra reaction after 3 months of treatment, patient increased weight, Ditophal was well tolerated, reaction most probably due to D.D.S. medication.

Clinically improved.

TREATMENT: 52 weeks Total of Ditophal: 156 tubes (780 grammes) Total of D.D.S.: $\quad 45.6 \mathrm{G}$.

No. 20110-Male-27 years of age.

Type of disease: Lepromatous leprosy 21/2 years sick before admittance.

Lepromin: Negative. Tuberculin: $10 \mathrm{~mm}$.

Hansen bacilli: On October, 1959 Skin: +++

$$
\begin{array}{ll}
\text { On February, } 1960 & \text { Skin: }++ \\
& \text { Nose Negative }
\end{array}
$$

Patient tolerated well the treatment, but left the hospital after 5 months; therefore this case is not suitable for evaluation.

Treatment: 37 weeks Total of Ditophal: 111 tubes (555 grammes)

Total of D.D.S.: $\quad 33.3 \mathrm{G}$. 
No. 20156-Female - 40 years of age.

Type of discase: Lepromatous leprosy-1 year sick before admitted.

Lepromin: Negative. Tuberculin: $10 \mathrm{~mm}$.

Hansen bacilli: On October, 1959 Skin: ++++

$\begin{array}{lll} & \text { Nose: } & ++ \\ \text { On October, } 1960 & \text { Skin: } & ++\end{array}$

Nose: $t$

Sedimentation rate October, 1959 40/75. October, 1960 15/37.

August 1960-reaction with two relapses. No considerable improvement.

Treatment: 52 weeks Total of Ditophal: 156 tubes ( 780 grammes)

Total of D.D.S.: $\quad 45.6 \mathrm{G}$.

No. 20186-Male-18 years of age.

Type of disease: Lepromatous leprosy - $1 \frac{1}{2}$ years sick before admittance.

Tuberculin: Negative. Lepromin: Negative.

Hansen bacilli: On October, 1959 Skin: +++

On October, 1960 Skin: Negative

Nose: Negative

Sedimentation rate: October, 1959 21/52. October 1960 20/47.

After 3 months of treatment patient developed reaction, most probably due to D.D.S. Patient feels better, clinically improved.

Treatment: 52 weeks Total of Ditophal: 156 tubes (780 grammes) Total of D.D.S.: $\quad 45.6 \mathrm{G}$.

No. 20274-Male-46 years of gae.

Type of disease: Lepromatous leprosy - 2 years sick before admittance.

Lepromin: Negative. Tuberculin: Netative.

Hansen bacilli: On October, 1959 Skin: ++++

$\begin{array}{ll} & \text { Nose: }++++ \\ \text { On October, } 1960 & \text { Skin: }+ \\ & \text { Nose: }+\end{array}$

Sedimentation rate: October, 1959 95/120. October, 1906 130/135

After 3 months patient suffered from reaction which relapsed 6 times-case is not improved.

Treatment: 51 weeks Total of Ditophal: 153 tubes (765 grammes) Total of D.D.S.: $45.5 \mathrm{G}$.

No. 20257-Male-12 years old.

Type of disease: Lepromatous leprosy -1 year sick before admittance.

Tuberculin: Negative. Lepromin: Negative.

Hansen bacilli: On October 1959 Skin. ++++

$$
\begin{array}{ll}
\text { On October, } 1960 & \text { Skin: Negative } \\
& \text { Nose: }++
\end{array}
$$

Sedimentation rate: October, 1959 5/20. July, 1960 4/10.

October, 1960 reaction besides treatment was well tolerated. Clinically improved.

TREATMENT: 52 weeks Total of Ditophal: 156 tubes (780 grammes)

Total of D.D.S.: $\quad 45.6 \mathrm{G}$.

No. 20187-Male-15 years old.

Type of disease: Lepromatous leprosy - 2 years sick before admittance.

Lepromin: Negative. Tuberculine: Negative.

Hansen bacilli: On October, 1959 Nose: ++

$\begin{array}{ll} & \text { Skin: }++ \\ \text { On October, 1960, } & \text { Nose: }+ \\ & \text { Skin: }++\end{array}$

Sedimentation rate: October, 1959 15/26. October, 1960. 25/45.

Clinically no improvement.

TREATMENT: 52 weeks Total of Ditophal: 152 tubes (760 grammes)

Total of D.D.S.: $\quad 45.6 \mathrm{G}$. 
Synopsis of Results with Ditophal in Lepromatous Cases

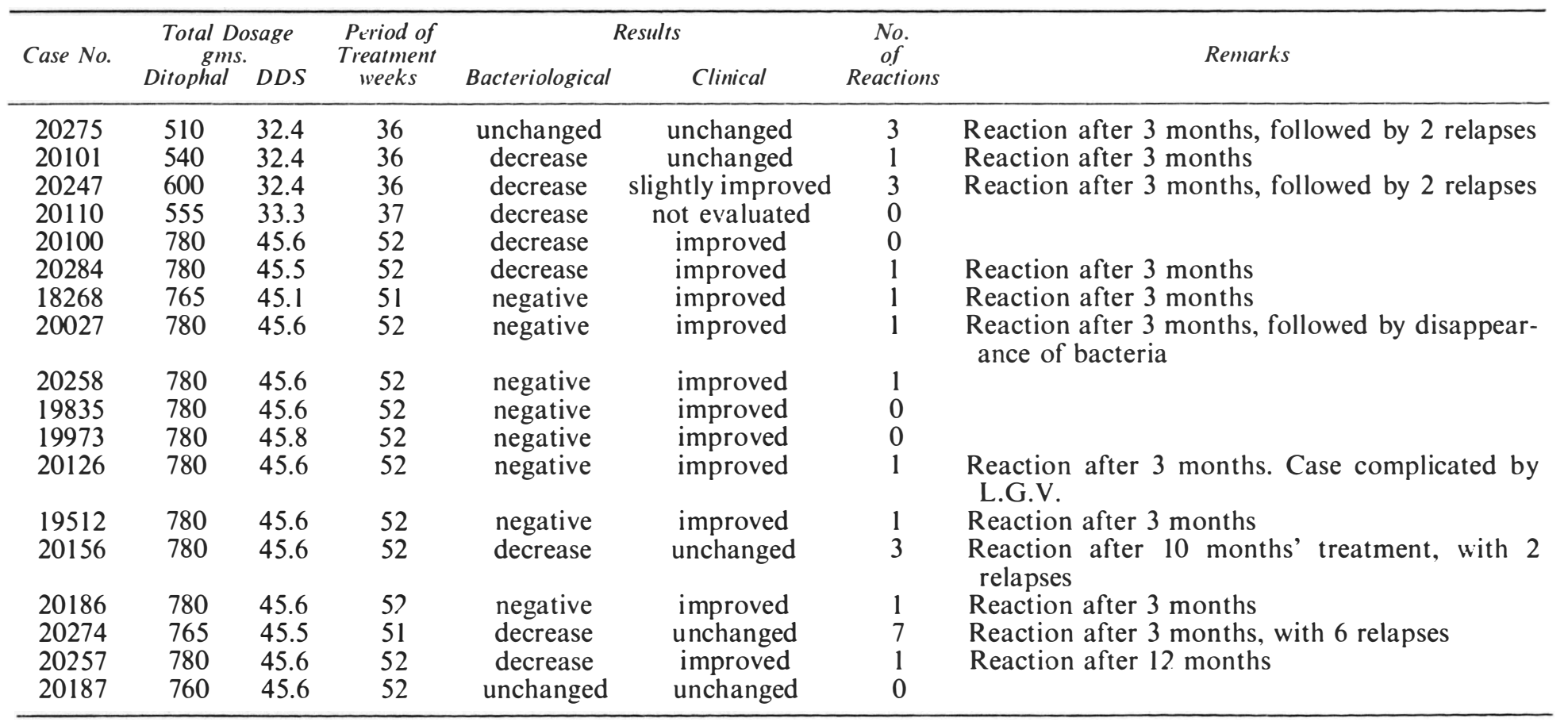




\section{Discussion of Results}

Lepra Reactions Of the 18 lepromatous cases, details of which are consolidated in Table I, only 5 did not experience reactions. Nine cases had one reaction, 4 patients had 3 or more reactions. In most cases, the reaction occured at the end of three months' treatment with DDS just at the time they were starting Ditophal inunction. Their reactions, therefore, may have been provoked by the DDS medication, although the contributory effect of Ditophal cannot be excluded.

Bacterial Examination Routine examinations of smears were carried out every two weeks. Reduction in the number of bacilli was seen in 16 cases and of these 9 cases progressed to negativity. Two cases showed no change in bacterial density but 1 of these 2 cases was only treated for 35 weeks. Histopathological findings (biopsies were carried out at intervals of 3 months) were in general agreement with the bacterial smears.

Clinical Evaluation Of the 14 lepromatous cases treated for 52 weeks, 12 cases showed marked improvement, the remaining 2 cases were not improved at all. Of the 4 lepromatous patients treated for only 36-37 weeks, 2 cases were not improved at all, 1 was only slightly improved, and the 4 th could not unfortunately be evaluated as he was a defaulter. The lack of improvement in this group may have been due to the fact that these cases were treated for a shorter period of time than the group treated for 52 weeks.

It is interesting to note that 1 case of tuberculoid leprosy, additional to the 18 cases already described treated for 52 weeks, suffered from a "reactionary phase" with bacillary index positive, followed by bacterial negativity and good clinical improvement when the reaction subsided.

Tolerance The inunction was well tolerated by all except 2 patients who showed skin reactions of papular type in the area inuncted. On withdrawal of Ditophal inunction for a few days, the reactions cleared up with no special treatment and they did not recur when inunctions were started again. No other side effects were seen with the drug.

\section{Summary}

1. The observation period in this investigation, being slightly more than one year, does not permit any final conclusion as to the lasting effect of the treatment.

2. The results so far indicate that the combined treatment, using DDS and Ditophal, yields more rapid results than in cases when standard treatment is given with DDS alone. 
3. No evidence of drug resistance has been encountered in our cases.

4. Patients in our series will continue to receive DDS alone when they have completed the year's treatment of Ditophal and DDS, and these cases will continue to be kept under observation as out-patients.

5. We consider that further studies are desirable, in both inpatients and out-patients, with a view to finding which combination of standard drugs and Ditophal inunction and for how long, offers the best and most practicable way of treating the disease.

\section{Acknowledgements}

We are grateful to Health Officer Ato Zerihun Desta of Princess Zenebe Work Hospital, Addis Ababa, for assistance in following up our cases.

\section{References}

1. Davey, T. F., "Progress with New Antileprosy Drugs", (November, 1958) Trans. of VII Int. Congr. Leprol. Tokyo, page 252.

2. Davey, T. F. and HogerzeIt., L. M., "Diethyl Dithiolisophthalate in the Treatment of Leprosy: A Progress Report", (1959) Leprosy Review., 30. 61 (1959), (Abst. Trop. Dis. Bull. 56, 536).

3. DaveY, T. F., "Diethyl Dithiolisophthalate in the Treatment of Leprosy; A second progress report", (1959), Leprosy Review, 30, 141.

4. Idem "Some recent chemotherapeutic work in Leprosy", (1960) Trans. Roy. Soc. Trop. Med. and Hyg. 54., 3., 199

5. Davies, G. E., Driver, G. W., Hoggarth, E., Martin, A. R., Paige, M. F. C., Rose, F. L. and WILSON, B. P., "Studies in the Chemotherapy of Tuberculosis: Ethyl Mercaptan and Related Compounds", Brit. J. Pharmacol., 11, 351 (1956)

6. Davies, G. E., and Driver, G. W., "The Anti-tuberculous Activity of Ethyl Thiolesters, with Particular Reference to Diethyl Dithiolisophthalate", (1957). Ibid, 12, 434.

7. Del Pianto, E., ("Chemotherapy of Tuberculosis with 2-mercapto-benzthiazole and its Derivatives together with Salts of $\mathrm{S}$ esters of Thiosulphuric Acid") (1950) Ricerca Sci, 20, 83.

8. Gabriel, M. H., 1959-60, Ann. Rep. Hlth. and Med. Serv., Queensland, 27.

9. Jamison, D. G. and Palmer, E., "Histological Changes in Leprosy and their modification by Treatment", (June 1960), Report, Sympos. on Leprosy Research, London. The Star, July-August, 1960.

10. LeChAT, M. F. "L'Utilisation pratique de l'Etisul (diethyl-dithiolisophthalate) pour le traitement de la lepre chez l'Africain", (1959) Ann. Soc. Belg. Med. Trop., 39, 865.

11. LoWE, J. S., "Metabolism of Compounds related to Ethyl Mercaptan", (1960) Biochem. Pharm., 3, 163.

12. MCGREGOR, H., "A preliminary trial of Etisul in the treatment of Leprosy patients", Leprosy Review, 32, 36. (1961)

13. Naguib, M. and Robson, J. M., "The Activity of Diethyl Dithiolisophthalate alone and combined with Izoniazid in the treatment of Murine Leprosy in the Mouse Cornea", (1956) Lancet, 1, 411,.

14. Ross, C. M. Telfer, J. F., and Hilton, D. D., "An Account of the use of Etisul in the treatment of Leprosy in the Northern Region of Nigeria", (1960) Leprosy Review. 31, 260.

15. SNOw, G. A., "The metabolism of compounds related to Ethanethiol", (1957) Biochem. J., 65, 77.

16. Thangaraj, R. H. and Thangaraj, S., "Treatment of Leprosy with Diethyl Dithiolisophthalate (ETIP or Etisul). Antiseptic (Madras)" March 1961. 